\title{
Book Review: Exodus. How Migration is Changing Our World
}

\section{Marek Loužek ${ }^{1}$}

Paul Collier, a professor of economics at the Oxford University, has already made a name for himself with a number of interesting books, such as "The Bottom Billion" (2007). This time, the topic he chose for his new book is migration - a topic sensitively monitored by the general public. Each individual exodus is a triumph of the human spirit, courage and ingenuity overcoming the bureaucratic barriers imposed by the fearful rich. But believing that migration only has bright sides would be a triumph of hope over experience.

In Collier's opinion, migration has been politicized before it has been analyzed. The movement of people from poor countries to rich ones is a simple economic process, but its effects are complex. Public policy on migration needs to come to terms with this complexity. Currently, policies toward migration vary enormously, both in countries of origin and host countries.

Migration is a subject on which almost everyone seems to have strong views. People can usually support their views with a smattering of analysis. In large part these views are derived from prior moral tastes rather than from superior command of the evidence. Evidence-based analysis is the strong suit of economics. Like many policy issues, migration has economic causes and consequences, and so economics is at the forefront of assessing policy.

For half a century following the outbreak of the First World War countries closed their borders. Wars and the Depression made migration practically difficult and immigrations unwelcome. By the 1960 s people overwhelmingly lived in the country in which they had been born. But during the half-century of immobility, there had been a dramatic change in the global economy: a gulf had opened up between the incomes of countries. Policies not only vary between countries, they oscillate between the open door favored by economists and the closed door favored by electorates. For example, in Britain the door was opened in the 1950s, partially closed in 1968, flung open again in 1997, and is now being closed again.

We know three big things about what drives international migration. One is that migration is an economic response to the gap in income other things being equal, the wider the gap in income, the stronger the pressure to migrate. The second is that there are a

\footnotetext{
${ }^{1}$ Associate professor at University of Economics, Department of Economic and Social Policy, Faculty of Economics. E-mail: louzek@ post.cz
}

C 2016 by the authors; licensee Review of Economic Perspectives / Národohospodárský obzor, Masaryk University, Faculty of Economics and Administration, Brno, Czech Republic. This article is an open access article distributed under the terms and conditions of the Creative Commons Attribution 3.0 license, Attribution - Non Commercial - No Derivatives. 
myriad of impediments to migration, economic, legal, and social, that are cumulatively important, so that migration is an investment: cost must be borne before benefits can be reaped. If the gap is wide because people in the country of origin are desperately poor, their desire to migrate is likely to be frustrated. The third big thing is that costs of migration are greatly eased by the presence in the host country of a diaspora from the country of origin. So the rate of migration is determined by the width of the gap, the level of income in countries of origin, and the size of the diaspora.

Any honest analysis of migration must recognize that there are both winners and losers, and that even determining the overall effect on a particular group can be ambiguous, depending on how gains are measured against losses. Collier analyses the impact of migration on three groups of people: the migrants themselves, the indigenous population of the host country, and the people left behind in the country of origin.

Firstly, migrants face costs of overcoming the barriers to movement that are substantial, but they reap economic benefits that are much larger than these costs. Migrants capture the lion's share of the economic gains from migration. The big gains accrue as a result of moving from a country in which workers are paid little to one in which they are paid a lot. By shifting a worker from a dysfunctional society to a more functional one, their productivity can increase tenfold. Many people cannot afford to migrate: it is a form of investment. Like all investments, costs have to be incurred up front, while benefits come gradually over time. The best time for migration is while the worker is still young.

Some new evidence indicates that these large economic gains are partly, or perhaps substantially, offset by psychological losses. For the typical migrant from a low-income country who comes to a high-income country, the income gain is overkill. Families are separated, and the migrant spends his life in a culturally alien environment. He may tune in to the radio from his home country, surround himself with friends from the diaspora, and return home annually, but day by day the absence from home may make him less happy.

The massive productivity gains from migration that so excite economists and that migrants capture appear not to translate into additional well-being. Migration does not deliver the anticipated free lunch, or rather the free lunch comes at the price of indigestion. As opposed to that, children of migrants grow up without the nostalgia of their parents. Migrants move for the benefit of their children rather than themselves.

Secondly, Collier examines the impact of migration on the host countries. The immigration of workers would be expected to reduce wages and increase the returns on capital. As a result, indigenous workers would be worse off and indigenous wealth owners would be better off. Migrants increase the diversity of society. In some respects this is beneficial: greater diversity brings greater variety and so brings stimulus and choice. But diversity also brings problems. This is because in a modern economy well-being is greatly enhanced by what might be described as mutual regard.

Migration produces diasporas, and diasporas produce migration. The prolonged period during the twentieth century in which the borders of rich countries were closed to migrants from poor countries implied that as of around 1960 there were no significant diasporas. Starting from 1960, migration preceded the buildup of diasporas. Because 
diasporas were initially negligible, despite the wide income gap, even once borders were opened, there was only modest migration.

Collier models a migration function where axis y represents the degree of migration and axis $\mathrm{x}$ represents the size of the diaspora. The larger the size of the diaspora is relative to the indigenous population, the smaller will be the proportion of its interactions with the indigenous. Even when there is no diaspora, there is some migration, because the income gap induces some people to relocate. But the larger the diaspora, the faster the migration from country of origin.

The income gap between poor countries and rich ones is wide and the global growth process will leave it wide for several decades. Migration will not significantly narrow this gap because the feedback mechanisms are too weak. Therefore, migration continues, diaspora will continue to accumulate for some decades. Thus, the income gap will persist, while the facilitator for migration will increase. The implication is that migration from poor countries to rich is set to accelerate.

Mutual regard, or sympathy, gives rise to feeling of loyalty and solidarity for those fellow members of our community who are less fortunate. The greater the proportion of immigrants in a community, the lower the mutual levels of trust were between immigrants and the indigenous population. In other words, far from proximity leading to greater mutual understanding, it leads to heightened mutual suspicion.

Migrants increase social diversity. Diversity enriches economies by bringing fresh perspectives for problem solving, and the variety it brings with it enhances the pleasures of life. But diversity also undermines mutual regard and its invaluable benefits of cooperation and generosity. The corrosive effects of diversity are accentuated if migrants are from countries with dysfunctional social models to which they remained attached. There is therefore a trade-off between the costs and benefits of diversity.

The third aspect, which Collier examines, is the impact of migration on the countries of origin. A badly governed country is likely to experience a lot of emigration: people who cannot vote with a ballot slip vote with their feet. The most common phrase used to describe them is "brain drain": emigration draws off the brightest, most ambitious, and most educated people from the society.

The possibility of emigration opens up life chances dramatically, not just for the migrant but for the entire family. In many cases migration is more a family decision than that of the migrant alone: the migrant is not escaping from the family but is part of a larger strategy of enlarging opportunities. From the perspective of other family members, migrants are investments that often pay off handsomely through a prolonged stream of remittances and enhanced access for further migration.

Therefore, Collier arrives at the conclusion that migration is good for those left behind. Poor choices in economic policy, dysfunctional ideologies, bad geography, negative attitudes about work, the legacy of colonialism, and a lack of education may result in massive migration. Workers who migrate from poor countries to rich ones are switching social models. As a result their productivity rockets upward.

So the implication is that while migration is helping those left behind, it would help even more, if there was less of it. But countries of origin cannot control emigration 
themselves: the rate is determined by the policies of host countries. The polemical debate, migration is good versus migration is bad, makes it much harder to frame an ideal policy: not a door that is open or closed, but one that is ajar.

Migration policies are set not by the governments of countries of origin but by those of host countries. In any democratic society, the government must reflect the interests of the majority of its citizens, but both the indigenous poor and those living in the poorest societies are of legitimate concern to citizens. Hence, in setting migration policy, host governments will need to balance the interests of the indigenous poor against the interests of migrants and of those left behind in poor countries.

An argument often invoked in favor of migration is that migrants are disproportionately innovative. A commonly cited figure is that in the US immigrants and their children account for a disproportionate number of patented inventions. In short, immigrants tend to be exceptional. However, the American experience may be due more to the exceptional nature of America, as a magnet for innovative entrepreneurs, than to the exceptional nature of migrants globally. Even if migrants are self-selected to be exceptional, then the gains for high-income countries are offset by losses for poor countries of origin. A talent transfer from poor societies to rich ones is not necessarily something that should be cause for global celebration.

However, immigrants are exceptional in one respect and that is crime. Across Europe, for a variety of reasons, foreigners tend to be heavily overrepresented in the prison population. France is fairly typical, with foreigners constituting around $6 \%$ of the overall population and $21 \%$ of the prison population. Higher proportions of foreigners in the prison population are also confirmed by German and British statistics.

Multiculturalism was framed more positively by liberal elites as desirable in itself: such a society provided more variety and stimulus than a society with a single culture. In this form multiculturalism embraces the permanent coexistence of distinct cultures in the same country. The nation is reconceived to be a geopolitical space in which separate cultural communities peaceably coexist with equal legal and social status.

In Europe, until recently the dominant tendency among political elites has been to espouse multiculturalism interpreted as the right to persistent cultural separatism. This orthodoxy and its supporting policies responded to, and legitimized, a preference for cultural separatism on the part of major groups of immigrants. While migration does not make nations obsolete, the continued acceleration of migration in conjunction with a policy of multiculturalism might potentially threaten their viability. Absorption has proved more difficult than anticipated.

Whether or not host populations have moral right to manage migration in their own interests, they currently have the legal right to do so. Since scarcely any governments claim he legal right to restrict exit, all controls on global migration flows are ultimately set by the perceived interests of host populations. However, although the high-income countries are democratic, their migration policies have often not reflected the views of the indigenous electorate. The rise of populist parties in Europe reflects the concerns of ordinary people about immigration. 
Only from the wilder shores of libertarianism and utilitarianism can it be argued that migration controls are ethically illegitimate. Extreme libertarianism denies the right of governments to restrict individual freedom, in this instance the freedom of movement. Universalist utilitarianism wants to maximize world utility by whatever means. The best possible outcome would be if the entire world population moved to the country in which people were most productive, leaving the rest of the earth empty. Evidently, neither of these philosophies provides an ethical framework by which a democratic society would wish to navigate migration policy.

In the absence of controls, migration and the diaspora would expand without limit. However, instead of leaving migration to accelerate until the point of policy panic, the governments of host countries now adopt a package of policies designed around ceiling, the selection of migrants, the integration of diasporas, and the legalization of illegal immigrants.

For unrestricted migration to be the moral principle for, say, African immigration to America, it must also be the principle for Chinese immigration to Africa. Yet most African societies are understandably extremely wary of unrestricted migration. Even the economists who extol the billions of dollars to be gained from the free movement of labor between countries do not literally advocate unrestricted migration.

In Collier's opinion, it is wrong to ask "Is migration bad or good?". Asking this question of migration is about as sensible as it would be to ask "Is eating bad or good?" In both cases the pertinent question is not bad or good but how much is best. Some migration is almost certainly better than no migration. But just as eating too much can lead to obesity, so migration can be excessive.

\section{References}

COLLIER, P. (2013) Exodus. How Migration is Changing Our World. Oxford - New York, Oxford University Press, 310 pages, ISBN 978-0-19-539865-6. 